\title{
Twin-Wire Pulsed Tandem Gas Metal Arc Welding of API X80 Steel Linepipe
}

\author{
Wenhao Wu $(\mathbb{D}$, Ming Zhao $\mathbb{D}$, Haiyan Wang $\mathbb{D}$, Yanxia Zhang $\mathbb{D}$, and Tong Wu $\mathbb{D}$ \\ College of Mechanical and Electrical Engineering, China University of Petroleum, East China, Qingdao, Shandong, China \\ Correspondence should be addressed to Ming Zhao; zhaoming08@upc.edu.cn
}

Received 12 December 2017; Accepted 5 February 2018; Published 11 March 2018

Academic Editor: Jerzy A. Szpunar

Copyright (c) 2018 Wenhao Wu et al. This is an open access article distributed under the Creative Commons Attribution License, which permits unrestricted use, distribution, and reproduction in any medium, provided the original work is properly cited.

\begin{abstract}
Twin-Wire Pulsed Tandem Gas Metal Arc Welding process with high welding production efficiency was used to join the girth weld seam of API X80 steel linepipe of $18.4 \mathrm{~mm}$ wall thickness and $1422 \mathrm{~mm}$ diameter. The macrostructure, microstructure, hardness, and electrochemical corrosion behavior of welded joints were studied. Effects of temperature and $\mathrm{Cl}^{-}$concentration on the corrosion behavior of base metal and weld metal were investigated. Results show that the welded joint has good morphology, mechanical properties, and corrosion resistance. The corrosion resistance of both the base metal and the weld metal decreases with increasing temperature or $\mathrm{Cl}^{-}$concentration. In the solution with high $\mathrm{Cl}^{-}$concentration, the base metal and weld metal are more susceptible to pitting. The corrosion resistance of the weld metal is slightly lower than that of the base metal.
\end{abstract}

\section{Introduction}

At present, API X80 pipeline steel offering super high strength and high toughness is widely used in the petrochemical industry [1]. This steel is also used extensively in the pipeline construction of West-East Gas Pipeline Projects in China [2]. Welding is a key process of long-distance oil and gas pipeline construction, which utilizes up to $20 \%$ of the total investment [3]. However, the recent increase in the strength of pipeline steel necessitates a thicker wall of pipeline, which results in poor weldability $[4,5]$. Therefore, welding of the ultrahigh strength pipeline steel is becoming an intricate task and needs urgent attention.

In the pipeline construction, high weld quality and high production efficiency are two essential requirements. However, these requirements are hardly fulfilled in the welding of girth weld seam of API X80 steel pipe using conventional gas metal arc welding (GMAW) process with single-wire and multilayer [6]. In GMAW, an increase in welding speed alone is unable to meet the required weld quality while an increase in heat input alone causes degradation of weld mechanical properties although it reduces the number of weld passes and increases the welding efficiency. Fortunately, the multiwire Pulsed Tandem Gas Metal Arc Welding (PT-GMAW) process has the potential to overcome the above problems while also meeting both aforesaid requirements [7-9]. Therefore, PTGMAW is a candidate welding process for application in the pipeline construction.

In practice, the welded linepipes are buried into soil for transporting oil or gas [10]. The pipeline in service encounters two different kinds of corrosive environments, the complex soil on the outer surface and the solution containing $\mathrm{H}_{2} \mathrm{~S}$, $\mathrm{Cl}^{-}, \mathrm{HCO}_{3}{ }^{-}$, and so on in the inner surface [11-13]. Published studies have shown that corrosion is one of the main causes of pipeline failure $[14,15]$. Therefore, a welded pipeline is immediately subjected to anticorrosion treatment. It is well known that the corrosion resistance is the key factor to ensure the safe operation of long-distance oil and gas pipelines [16]. However, the microstructure and composition of the welded joints are severely inhomogeneous, and this inhomogeneity is coupled with the welding residual stress. Thus, the welded joint becomes the weakest part of the pipeline with respect to the corrosion resistance $[17,18]$. Therefore, the study of welding technology and corrosion resistance of longitudinal or circumferential welds of high strength and high toughness steel pipelines is one of the current hotspots.

In this study, twin-wire PT-GMAW of API X80 pipeline steel has been introduced. The quality and performance of 


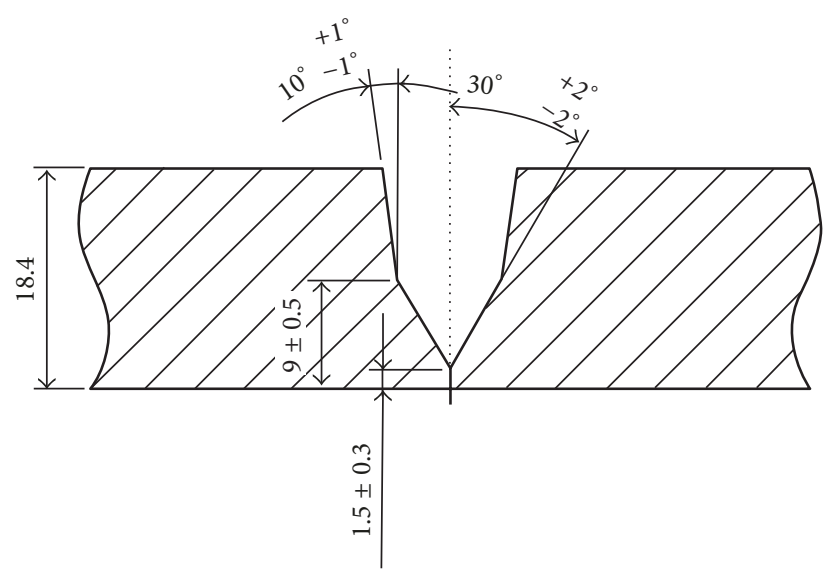

FIGURE 1: Schematic of the double-V groove (unit: $\mathrm{mm}$ ).

welded linepipes are evaluated and optimized through analysis of macrostructure, microstructure, mechanical properties, and corrosion behavior of the base metal and weld metal. The effects of external soil temperature and concentration of internal corrosive solution on the corrosion behavior of the base metal and weld metal are explored. This work is expected to hold significant theoretical and practical importance in the petrochemical industry.

\section{Materials and Methods}

\subsection{Welding Experiment}

2.1.1. Chemical Composition and Properties of API X80. API X80 steel linepipes, each with diameter $1422 \mathrm{~mm}$ and wall thickness $18.4 \mathrm{~mm}$, were used in this welding experiment. The chemical compositions and mechanical properties of the above steel are given in Tables 1 and 2, respectively.

2.1.2. Groove of Girth Weld Seam. Two circular pipes were girth-welded together. Machining parameters of the double$\mathrm{V}$ groove are shown in Figure 1. The angles of the 1st and the 2 nd V-grooves are $\sim 60^{\circ}$ and $\sim 80^{\circ}$, respectively. In order to strike the welding arc easily and reduce the amount of deposited metal, the gap was made as narrow as possible.

2.1.3. Welding Parameters. Twin-wire PT-GMAW was used to weld the API X80 steel line pipes. The welding setup consisted of two sets of wire feeding systems (one leading the other), two pulsed MIG 500 power sources, and a series of controlling equipment. The shielding gas, composed of $80 \%$ Argon and $20 \% \mathrm{CO}_{2}$, was combined with a flux cored wire to generate the slag and gas protection. For this, a flux-cored wire AWS A 5.29 E81T8-Ni2 with diameter of $2.0 \mathrm{~mm}$ was used as the welding consumable. Welding parameters used in the process were optimized to improve the weld quality and are listed in Table 3. The welding process comprised five passes: one root pass, that is, the first layer of the girth weld seam, followed by one hot pass, that is, the second layer of the girth weld seam, and three subsequent passes, that is, 2 filler passes and 1 cap pass. The root pass and the hot pass were made by depositing the leading wire and trailing wire, respectively, while the other three passes were made by depositing two wires of the PT-GMAW. Preheating and interpass temperatures were strictly controlled in the range of $100^{\circ} \mathrm{C} \sim 150^{\circ} \mathrm{C}$.

2.2. Hardness Test. According to ASTM E92, the macroVickers hardness test was performed with a constant force of $10 \mathrm{kgf}$. The maximum deviation of the hardness measurements HV10 was $\pm 3 \%$. Details to the location of the tested paths are illustrated in Figure 2.

\subsection{Electrochemical Corrosion Test}

2.3.1. Corrosion Specimen. For electrochemical corrosion test, rectangular specimens were taken from both the weld metal and base metal. Each specimen was of dimensions $(10 \mathrm{~mm})_{L} \times(10 \mathrm{~mm})_{W} \times(3 \mathrm{~mm})_{T}$. Using a soldering iron, a somewhat oversized electrical copper wire was soldered onto the back of each specimen. Then, all the specimens were mounted on silica gel, grinded using emery papers, and polished to mirror finish. Finally, the polished specimens were cleaned with acetone and alcohol and dried with a hair dryer.

2.3.2. Corrosion Solutions. Two types of solutions were used for the analysis of corrosion behavior of the welded linepipe because the interior and exterior surfaces of the linepipes experience two different types of corrosive environments. The corrosive solution used for the interior surface was an aqueous mixture of $0.5 \mathrm{~mol} \mathrm{Na}_{2} \mathrm{CO} 3$ and $1 \mathrm{~mol} \mathrm{NaHCO}_{3}$ with $\mathrm{pH} 9.4$ while that for the exterior surface was a Korla soil simulated solution [19] with the compositions shown in Table 4 and $\mathrm{pH} 8.4$ at room temperature. These solutions were prepared from pure chemical reagents and deionized water. For a given surface, that is, either interior or exterior, similar solution was used for the base metal and weld metal.

2.3.3. Test Equipment and Procedure. An electrochemical workstation comprising three electrodes was used as the corrosion test equipment. In this equipment, saturated calomel 


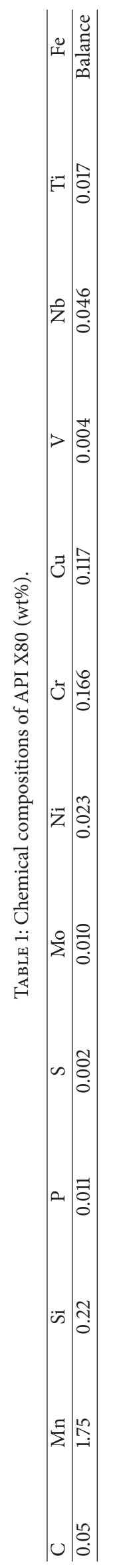




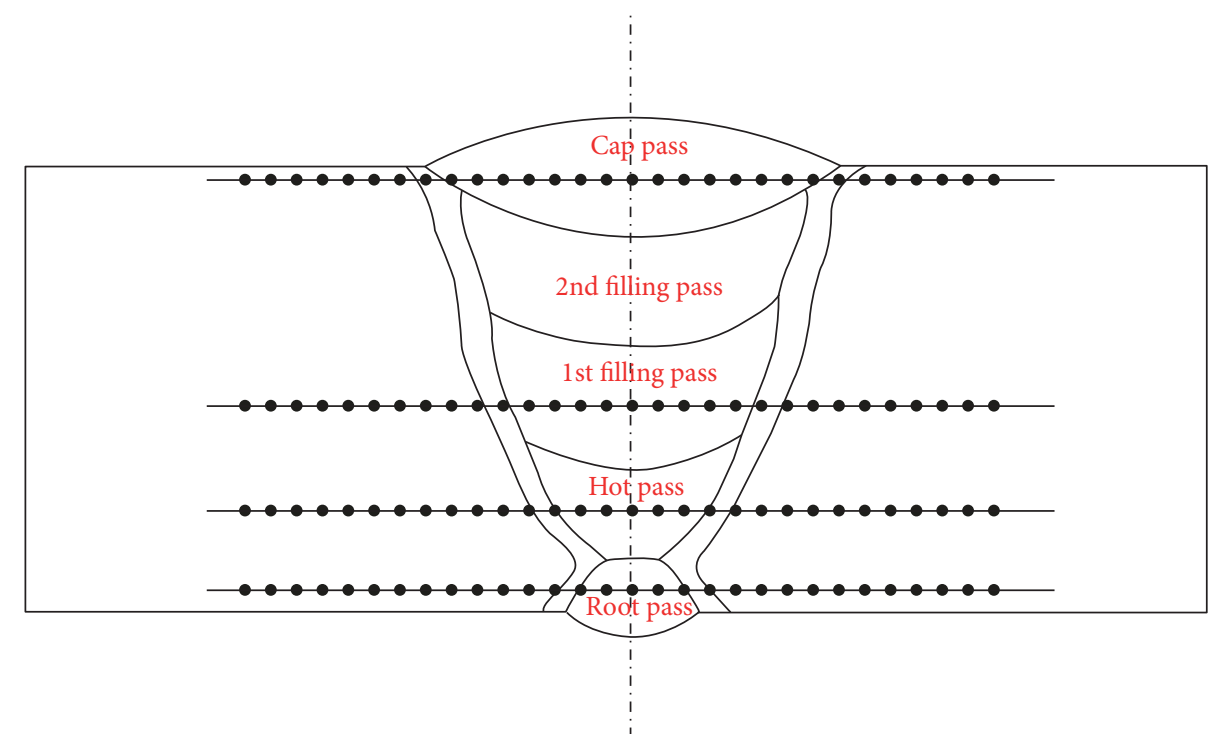

FIGURE 2: Schematic of tested paths for Vickers hardness.

TABLE 2: Mechanical properties of API X80 $\left(20^{\circ} \mathrm{C}\right)$.

\begin{tabular}{lc}
\hline Parameter & Value \\
\hline Yield strength $R_{\mathrm{p} 0.2} / \mathrm{MPa}$ & $\geq 550$ \\
Tensile strength $R_{m} / \mathrm{MPa}$ & $\geq 620$ \\
Elongation $A / \%$ & $\geq 20$ \\
Average absorbed energy CVN/J & $\geq 70$ \\
\hline
\end{tabular}

electrode and carbon rod were chosen as the reference and auxiliary electrodes, respectively, while the specimen was used as the working electrode. After stabilizing the open circuit potential of the setup, electrochemical impedance spectroscopy (EIS) and polarization (potentiodynamic scanning) experiments were conducted within a frequency range $10^{-2}-10^{5} \mathrm{~Hz}$ and scanning potential range $-1.5-1.2 \mathrm{~V}$. The scanning rate adopted was $1 \mathrm{mV} / \mathrm{s}$ in the higher-pH solution and $0.5 \mathrm{mV} / \mathrm{s}$ in the Korla soil simulated solution. Most of the corrosion tests were carried out at room temperature $\left(20^{\circ} \mathrm{C}\right)$ except for those aimed to investigate the influence of temperature on the corrosion behavior. In the latter case, tests were carried out also at temperatures $40^{\circ} \mathrm{C}$ and $60^{\circ} \mathrm{C}$. For each testing condition, at least 3 parallel tests were performed. All the measured values of the potential were relative to the saturated calomel electrode, and the test results were reproducible.

\section{Results and Discussion}

\subsection{Weld Morphology}

3.1.1. Macrograph of Welded Joint. Macrograph of the twinwire PT-GMA welded API X80 steel linepipe joint is shown in Figure 3. It can be found that the double-V groove is filled completely by the five deposited layers. Comparing to the conventional welding process widely used in the West-East
Gas Pipeline Project in China [6], Referred to Figure 4, it indicates that the welding efficiency of the girth weld seam has been improved significantly using the twin-wire PTGMAW.

3.1.2. Microstructure of Welded Joint. Microstructures of the base metal (BM), weld metal (WM), and heat affected zone (HAZ) are shown in Figure $4 \mathrm{a}$ through c, respectively. The BM microstructure (Figure 5(a)) comprises acicular ferrite (AF) and polygonal ferrite (PF). Grains within the BM are very fine and uniformly distributed. The microstructure of WM (Figure 5(b)) also constitutes the AF and PF and refined grains although the refinement is relatively less as compared to that within the BM. In addition, a significant amount of grain interlocking can be observed within the WM. The grain interlocking is of great significance to ensure the performance of welded joint. The HAZ microstructure (Figure 5(c)) constitutes a large amount of granular bainites (GB), a relatively small amount of lath-shaped bainites (LB) and randomly distributed martensite-austenite constituents (M-A). The grains within the HAZ are much coarser than those in the BM and WM. These coarse grains give rise to higher microstructure inhomogeneity and, thus, may deteriorate the performance of the welded joint.

3.2. Hardness of Welded Joint. Figures 6(a)-6(d) show the macro-hardness profiles of the root pass, hot pass, filling layer, and cap layer, respectively. Almost on every studied layer, average value of macro-hardness is the minimum in the HAZ and varies in the following order: $\mathrm{HAZ}<\mathrm{WM}<$ $\mathrm{BM}$. The average macro-hardness in the BM is slightly higher than that in the WM because the grains within the BM are relatively fine and more uniformly distributed, as observed in Figure 5. The hardness of the cap layer is slightly lower than the other layers. The reason is that the former layer had been heat treated by the latter, making the microstructure of the previous layer better to improve its hardness. 
TABLE 3: Welding parameters.

\begin{tabular}{lccc}
\hline Welding pass & Welding current $I / \mathrm{A}$ & Arc voltage $U / \mathrm{V}$ & Velocity $v / \mathrm{m}^{\mathrm{min}}{ }^{-1}$ \\
\hline Root & 240 & 27 & 0.8 \\
Hot & 240 & 27 & 0.5 \\
1st filler & & & 0.3 \\
$\quad$ Leading wire & 210 & 28 & 30 \\
$\quad$ Trailing wire & 190 & & 28 \\
2nd filler & 210 & 30 & 0.3 \\
$\quad$ Leading wire & 190 & & 0.3 \\
$\quad$ Trailing wire & & 28 & 30 \\
Cap & 210 & & \\
$\quad$ Leading wire & 190 & & \\
$\quad$ Trailing wire & & & \\
\hline
\end{tabular}

TABLE 4: Composition of the Korla soil simulated solution (g/L).

\begin{tabular}{lccccc}
\hline $\mathrm{NaHCO}_{3}$ & $\mathrm{KCl}$ & $\mathrm{Na}_{2} \mathrm{SO}_{4}$ & $\mathrm{CaCl}_{2}$ & $\mathrm{NaCl}_{2}$ & $\mathrm{MgCl}_{2} \cdot 6 \mathrm{H}_{2} \mathrm{O}$ \\
\hline 0.1462 & 0.2156 & 2.5276 & 0.2442 & 3.1703 & 0.6699 \\
\hline
\end{tabular}

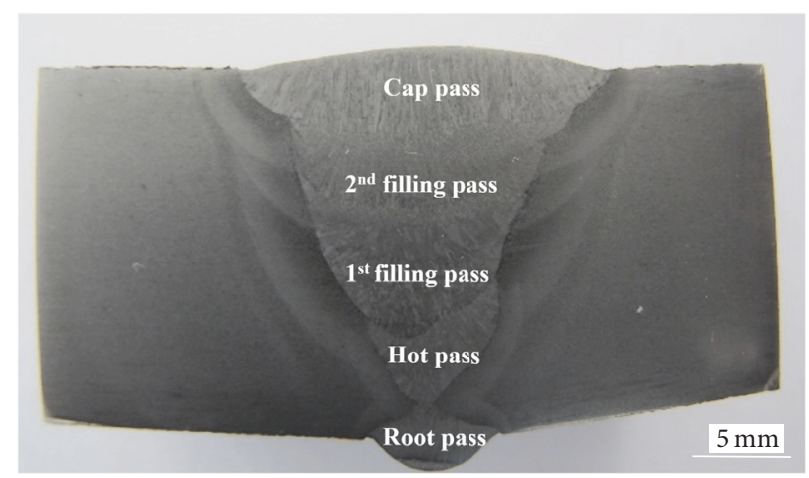

FIGURE 3: Macrograph of the PT-GMAW joint with 5 layers.

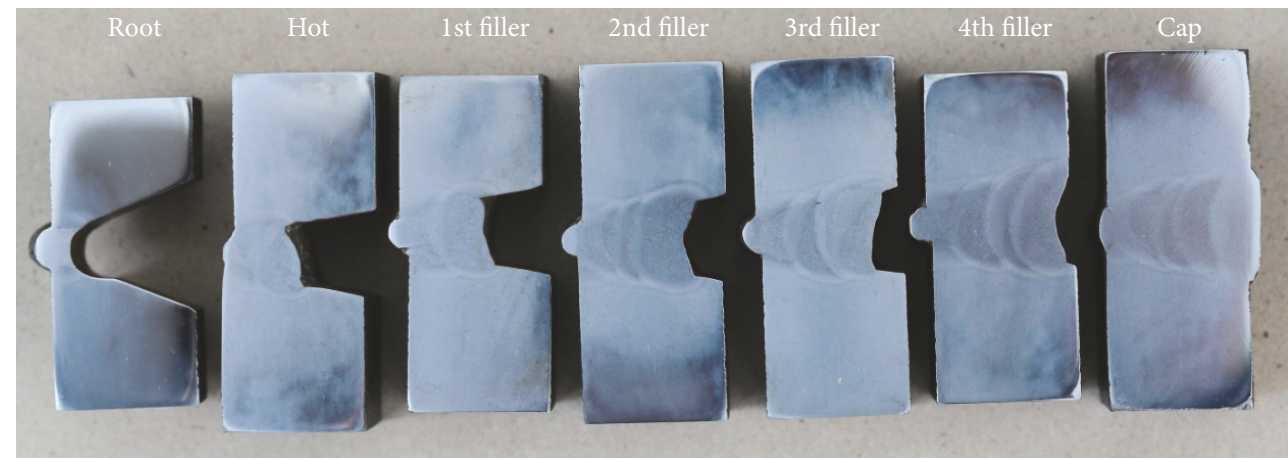

FIGURE 4: Macrograph of welding species of the combined girth-welded joint with 7 layers [6].

\subsection{Corrosion Behavior of Welded Joint}

3.3.1. Analysis of Corrosion Resistance. The polarization curves and EIS results of the BM and WM in the high $\mathrm{pH}$ solution are shown in Figures $7(\mathrm{a})$ and $7(\mathrm{~b})$, respectively. It can be observed that both the BM and the WM are markedly passivated. From Figure 7(a), it is apparent that the selfcorrosion current density and the corrosion potential of $\mathrm{BM}$ are $13.201 \mu \mathrm{A} \cdot \mathrm{cm}^{-2}$ and $-0.862 \mathrm{~V}$, respectively, while those values for the $\mathrm{WM}$ are $16.657 \mu \mathrm{A} \cdot \mathrm{cm}^{-2}$ and $-0.877 \mathrm{~V}$, respectively. Therefore, the WM has a more negative corrosion potential than the BM. This indicates that the WM is more 


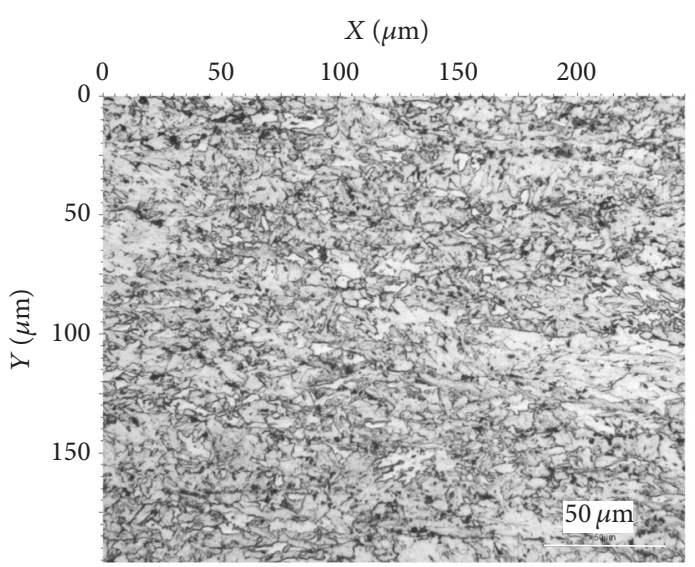

(a)

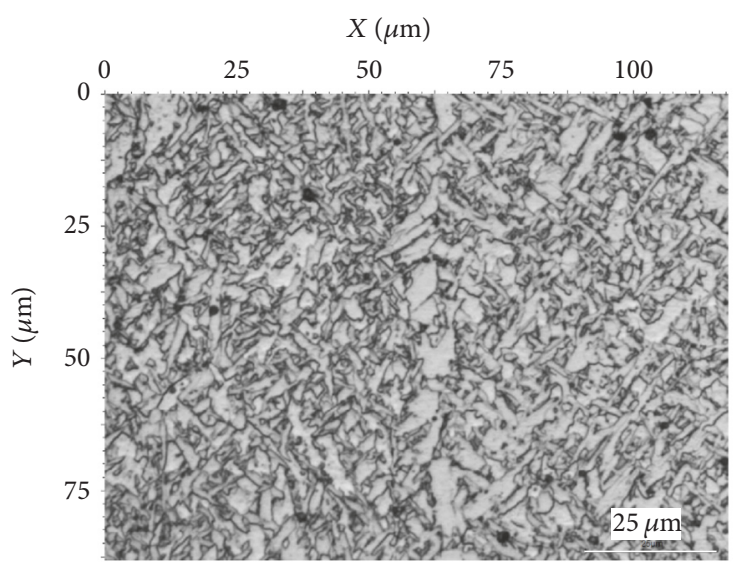

(b)

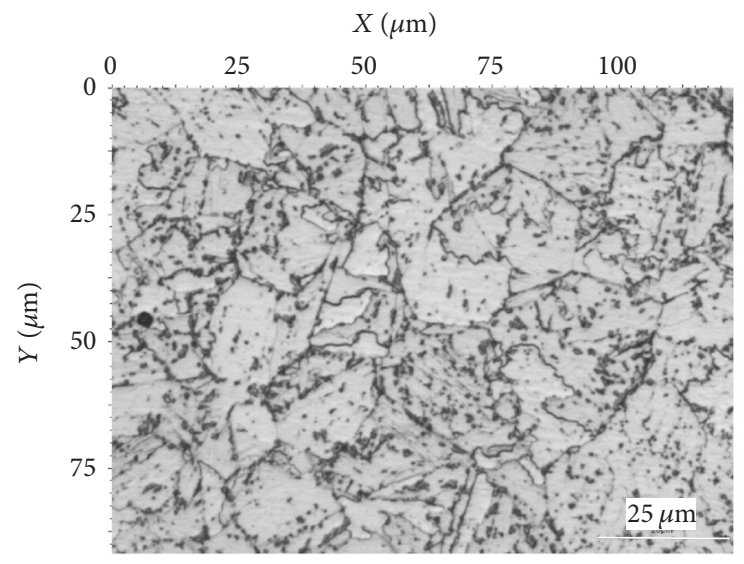

(c)

FIGURE 5: Microstructure of welded joint within (a) BM (×500), (b) WM (×1000), and (c) HAZ (×1000).

likely to be corroded than the BM. That is to say, the corrosion resistance of WM is lower than that of $\mathrm{BM}$ in the high $\mathrm{pH}$ solution. Moreover, the capacitive reactance arcs of the WM and BM (Figure 7(b)) are located in the first quadrant. This observation suggests that the reaction resistance of the BM is higher than that of the WM. This further indicates that the corrosion rate of $\mathrm{BM}$ is lower than that of the WM in the high $\mathrm{pH}$ solution.

The results of EIS were fitted using the equivalent circuit $R_{s}\left(Q_{f}\left(R_{f}\left(Q_{\mathrm{dl}} R_{c t}\right)\right)\right.$. In the circuit, $R_{s}$ is the solution resistance, $Q_{f}$ is the capacitance of the corrosion product film, $R_{f}$ is the resistance of the corrosion products at the electrode surface, $Q_{\mathrm{dl}}$ is the double layer capacitance, and $R_{c t}$ is the polarization resistance. In general, the greater is the value of $R_{c t}$, the harder is the feasibility of electrode reaction and, hence, the better is the corrosion resistance of the material [20]. $R_{c t}$ of the BM and the WM are $33380 \Omega \cdot \mathrm{cm}^{2}$ and $10380 \Omega \cdot \mathrm{cm}^{2}$, respectively. It can be seen that the polarization resistance of the WM is much smaller than that of the $\mathrm{BM}$, which indicates that the charge on the WM is easier to transfer; that is, the corrosion resistance of the WM is poorer than the BM. This assertion is consistent with that obtained from the observations from the polarization curves in Figure 7(a).

The polarization curves of the BM and WM in the Korla soil simulated solution, shown in Figure 8(a), are similar to each other. No passivation phenomena can be observed at their anodes, and only the active zones are corroded. The selfcorrosion current density and corrosion potential of the BM are $39.537 \mu \mathrm{A} \cdot \mathrm{cm}^{-2}$ and $-0.688 \mathrm{~V}$, respectively, and those of the $\mathrm{WM}$ are $41.602 \mu \mathrm{A} \cdot \mathrm{cm}^{-2}$ and $-0.769 \mathrm{~V}$, respectively. The marginal increase in the negative value of corrosion potential of BM indicates that its corrosion resistance is slightly higher than that of the WM in the Korla soil simulated solution.

The results of EIS in Figure 8(b) show that the capacitive reactance arc of the $\mathrm{BM}$ is greater than that of the WM. This indicates that BM exhibits a greater reaction resistance and, hence, a lower corrosion rate. The results of EIS were fitted with the equivalent circuit $R_{s}\left(Q_{\mathrm{dl}} R_{c t}\right)$ [21]. The fitted results are shown in Table 5. From the data in Table 5, it can be found that the charge transfer resistance of the BM is greater than that of the WM. Therefore, the corrosion resistance of BM is better than that of WM. This assertion is consistent with that obtained from the analysis of polarization curves. 


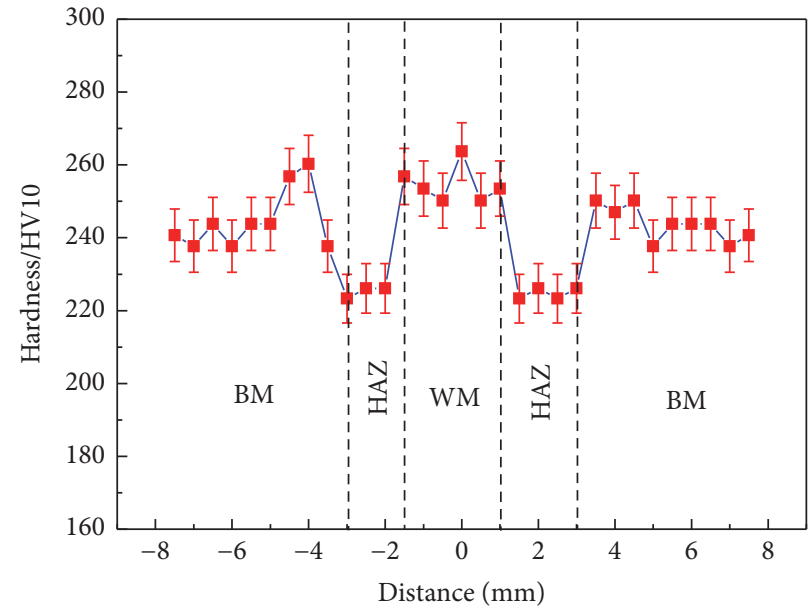

(a)

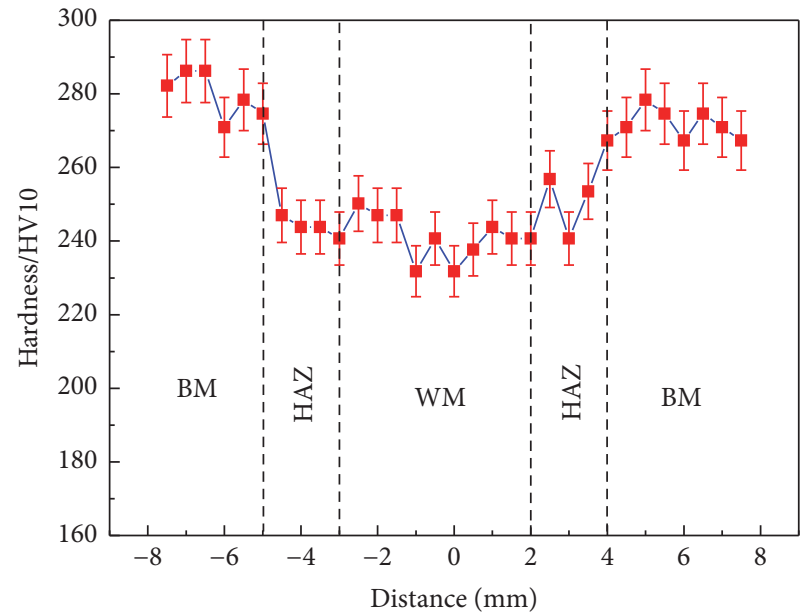

(c)

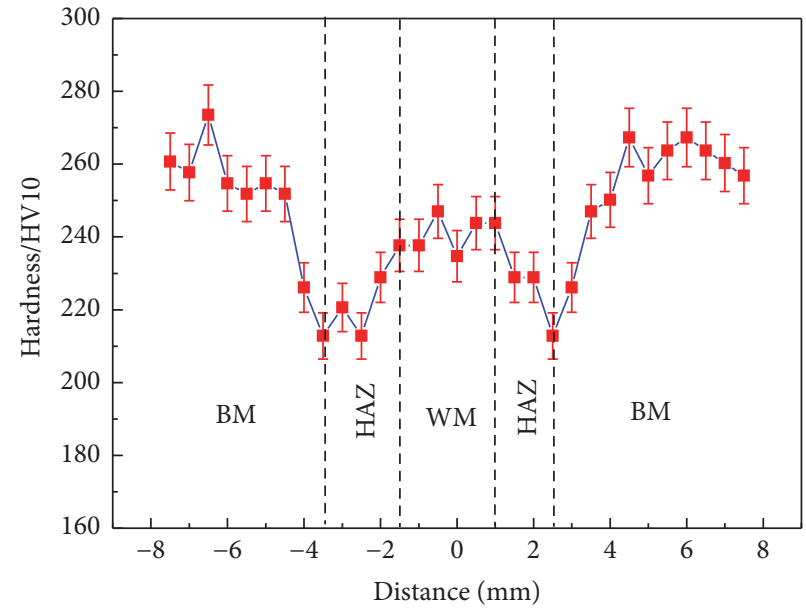

(b)

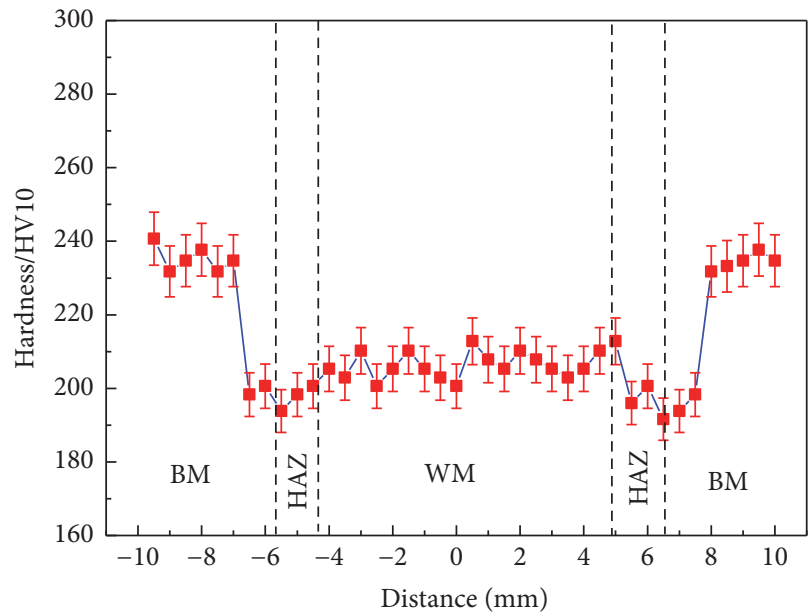

(d)

Figure 6: Macro hardness of welded joint within (a) root pass, (b) hot pass, (c) filling layer, and (d) cap layer.

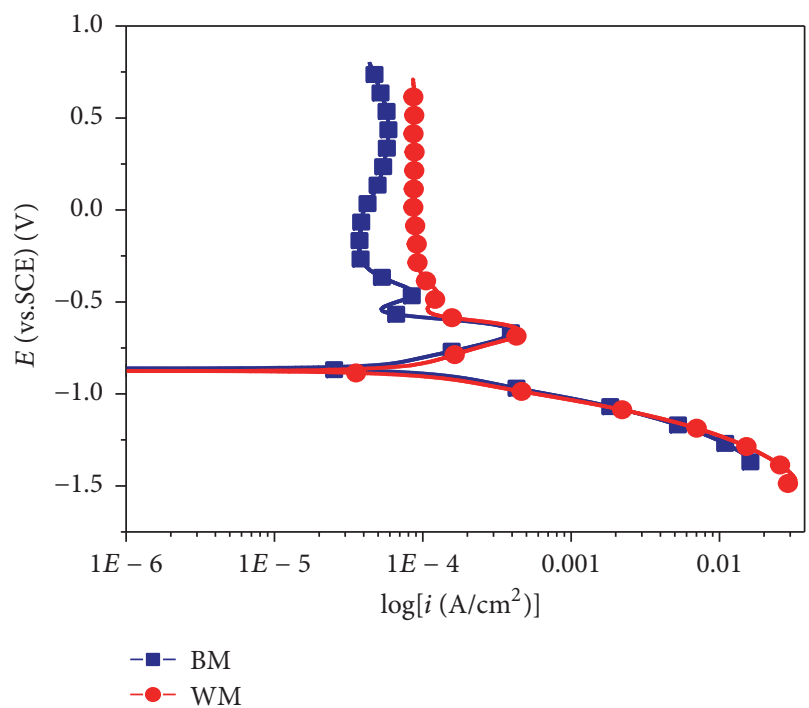

(a)

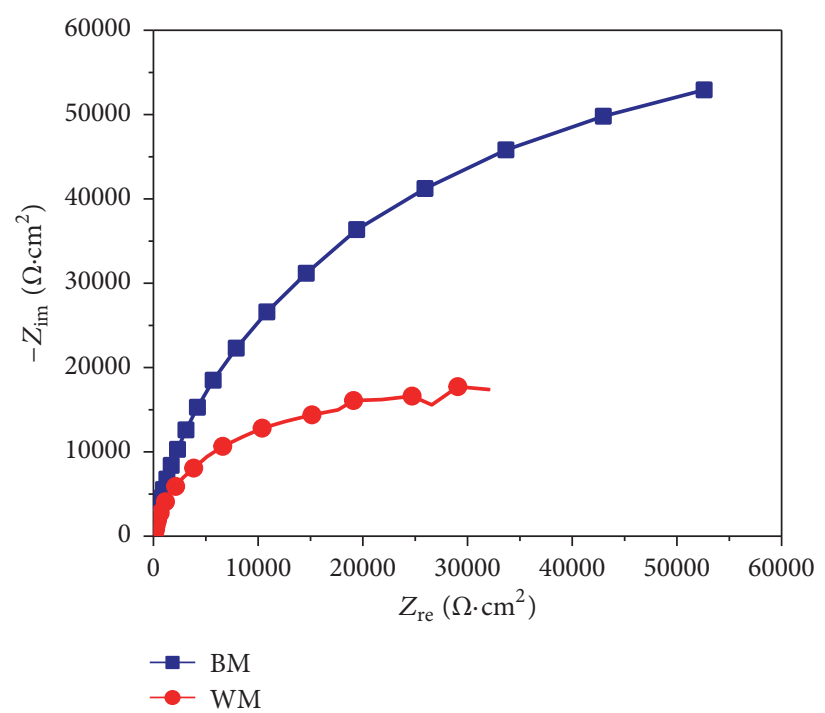

(b)

FIGURE 7: Results of electrochemical corrosion test of BM and WM in the high pH solution. (a) Polarization curves and (b) EIS. 


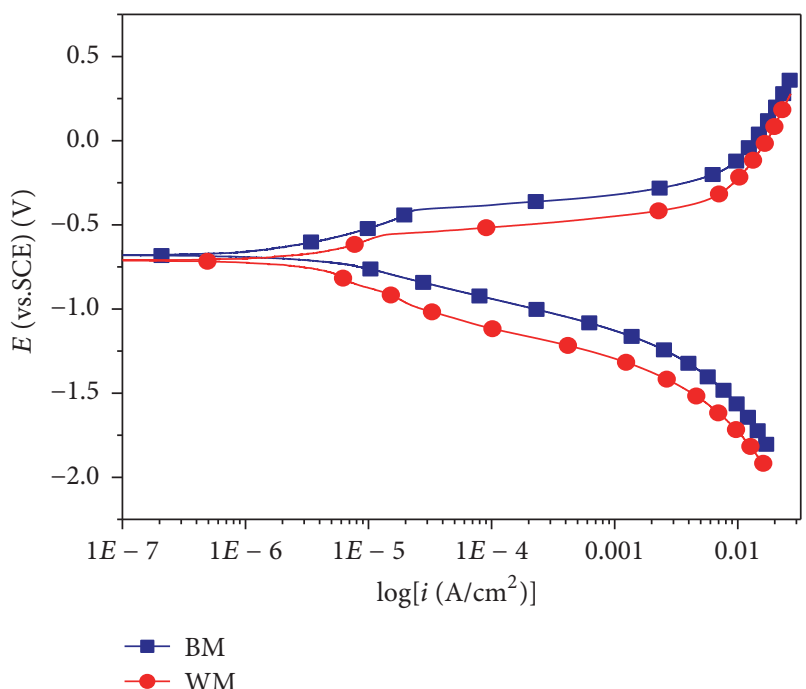

(a)

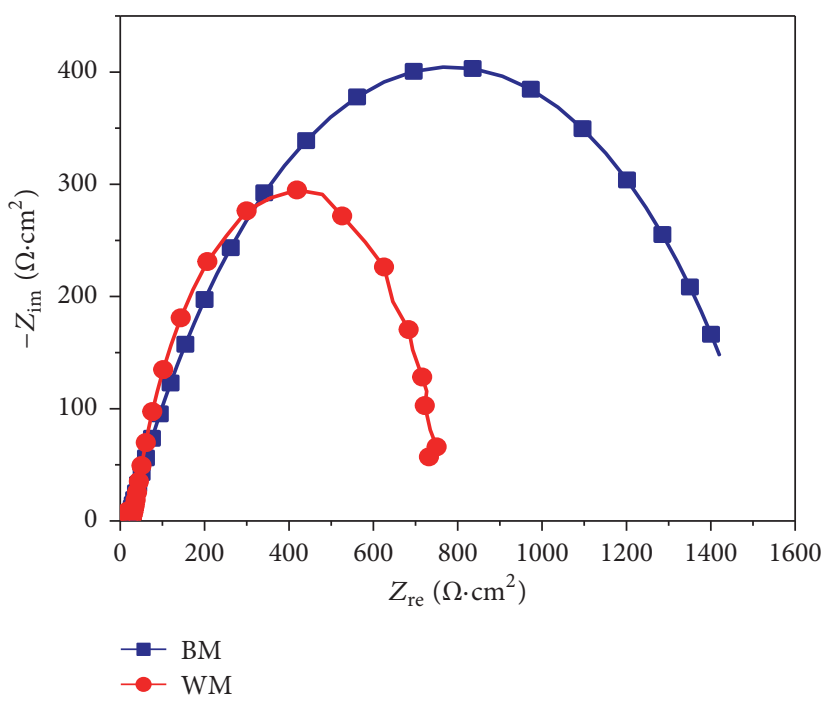

(b)

FIGURE 8: Results of electrochemical corrosion test of BM and WM in the Korla soil simulated solution. (a) Polarization curves and (b) EIS.

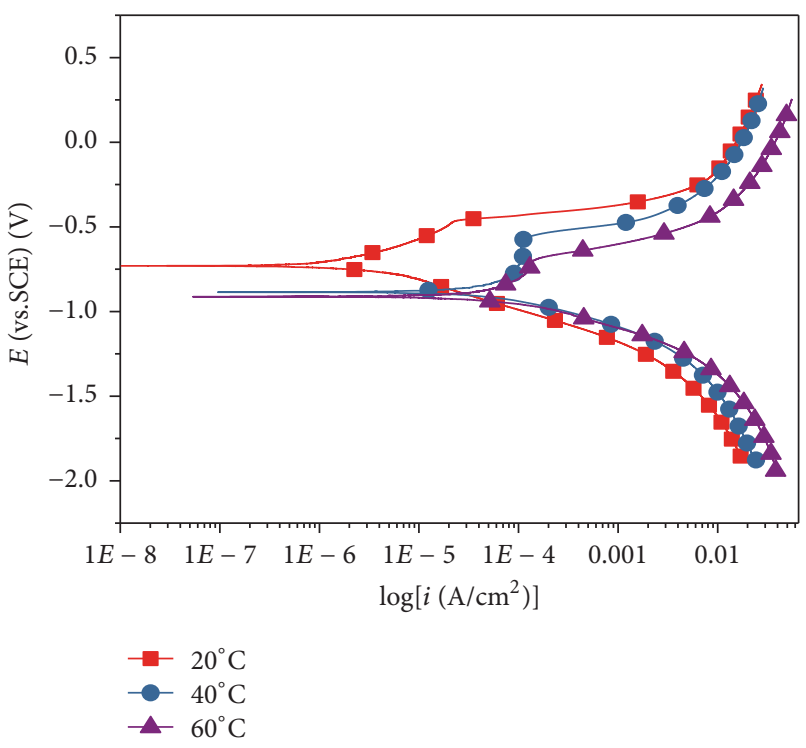

(a)

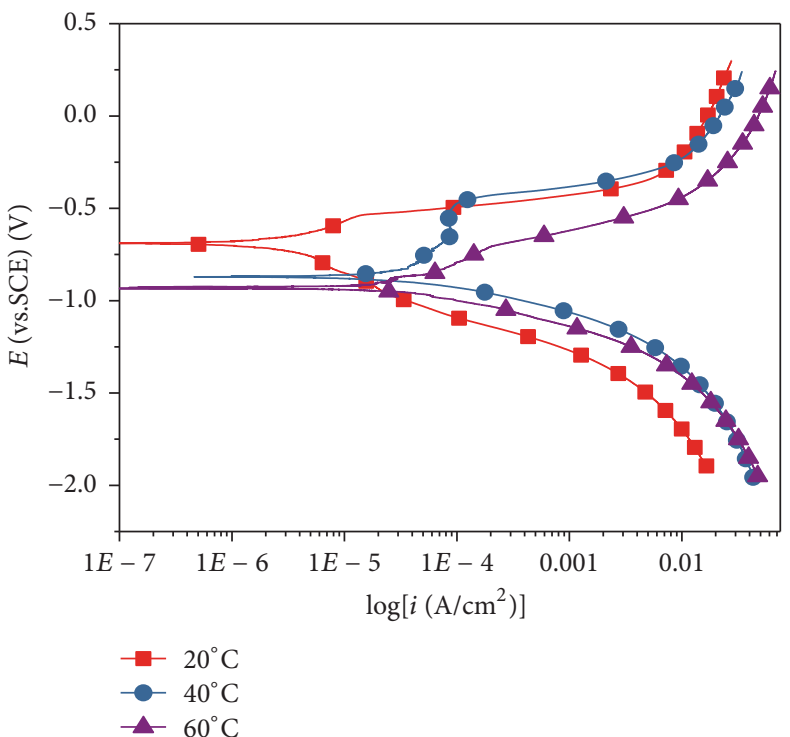

(b)

FIGURE 9: Influence of temperature on the polarization curve of (a) BM and (b) WM.

TABLE 5: Fitted results of EIS in the Korla soil simulated solution.

\begin{tabular}{lcccc}
\hline & $\begin{array}{c}\text { Solution resistance } R_{s} \\
\left(\Omega \cdot \mathrm{cm}^{2}\right)\end{array}$ & $\begin{array}{c}\text { Double layer capacitance } \\
Q_{\mathrm{dl}}\left(\Omega^{-1} \cdot \mathrm{cm}^{-2} \cdot \mathrm{S}^{n}\right)\end{array}$ & Diffusion index $n_{\mathrm{dl}}$ & $\begin{array}{c}\text { Polarization resistance } \\
R_{c t}\left(\Omega \cdot \mathrm{cm}^{2}\right)\end{array}$ \\
\hline BM & 19.29 & $4.9637 \times 10^{-4}$ & 0.620 & 1524 \\
WM & 23.61 & $8.2786 \times 10^{-4}$ & 0.754 & 766.4 \\
\hline
\end{tabular}

3.3.2. Influence of Temperature. The effect of temperature of the Korla soil simulated solution on the corrosion resistance of BM and WM is shown in Figures 9(a) and 9(b), respectively. With increase in temperature, the polarization curves of both the BM and the WM have shifted downwards, indicating a decrease in the self-corrosion potential of BM and WM. In other words, the corrosion tendencies as well as the corrosion current densities of both the BM and the WM have increased. These are clear indications of increase in the corrosion rate. Therefore, it can be asserted that the corrosion resistance of the BM and the WM decreases with increasing temperature. 


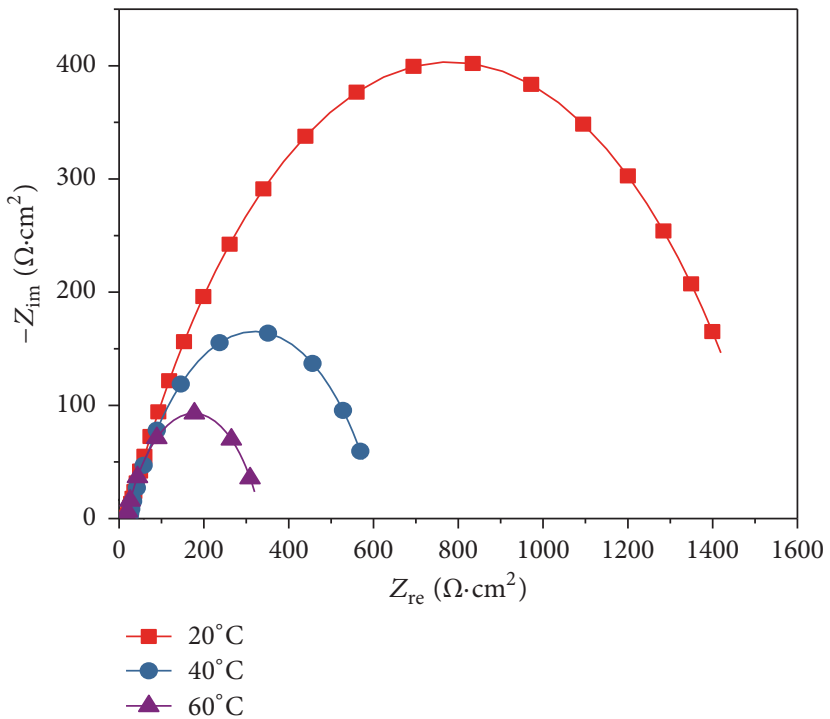

(a)

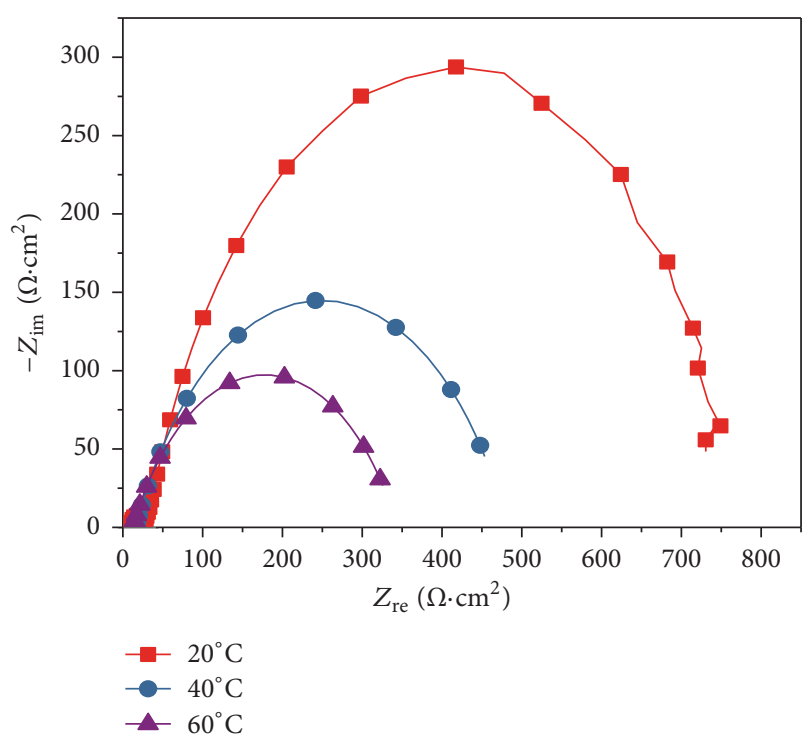

(b)

FIGURE 10: Influence of temperature on EIS profiles of (a) BM and (b) WM.

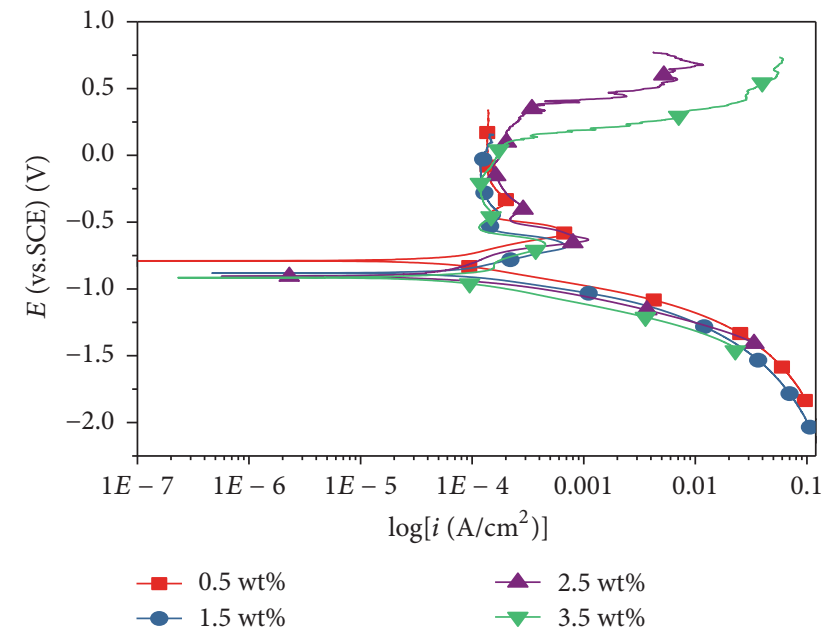

(a)

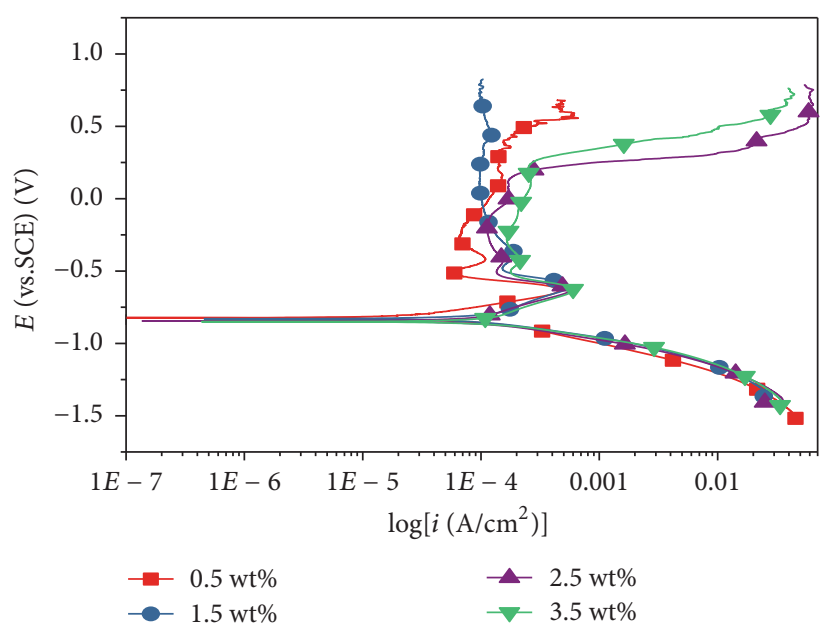

(b)

FIGURE 11: Influence of $\mathrm{Cl}^{-}$concentration on polarization curves of (a) BM and (b) WM.

Figure 10 shows the results of EIS of BM and WM at different temperatures of the Korla soil simulated solution. An apparent decrease in the diameter of the capacitance arc can be observed with the increase in temperature. This indicates a decrease in the resistance of electrode to chemical reaction or an easier corrosion reaction because of a decrease in the corrosion resistance of both the BM and WM. Moreover, the corrosion resistance of the $\mathrm{BM}$ is found to be better than that of the WM at all the temperatures under consideration. The above observations are consistent with those from the polarization curves.

3.3.3. Influence of $\mathrm{Cl}^{-}$Concentration. In order to study the effect of $\mathrm{Cl}^{-}$concentration on the corrosion resistance of $\mathrm{BM}$ and $\mathrm{WM}, 0.5 \mathrm{wt} \%, 1.5 \mathrm{wt} \%, 2.5 \mathrm{wt} \%$, and $3.5 \mathrm{wt} \% \mathrm{NaCl}$ solutions were added to the high $\mathrm{pH}$ solution. The polarization curves of $\mathrm{BM}$ and $\mathrm{WM}$ at $20^{\circ} \mathrm{C}$ are shown in Figure 11. No pitting has been found in the BM and WM with the addition of $0.5 \mathrm{wt} \% \mathrm{NaCl}$ solution. However, with a further increase of $\mathrm{Cl}^{-}$concentration in the high $\mathrm{pH}$ solution, that is, with the addition of 1.5 to $3.5 \mathrm{wt} \% \mathrm{NaCl}$ solutions, significant pitting of BM and WM has been observed, as evident in the macroscopic morphologies of BM and WM in Figure 12. From Figure 11, it is clear that both the pitting potential and the passivation potential decrease with increasing $\mathrm{Cl}^{-}$ concentration. This indicates a relatively easy path for the formation and growth of pit on the surface or a higher susceptibility to pitting. It can be inferred that increase in $\mathrm{Cl}^{-}$ 


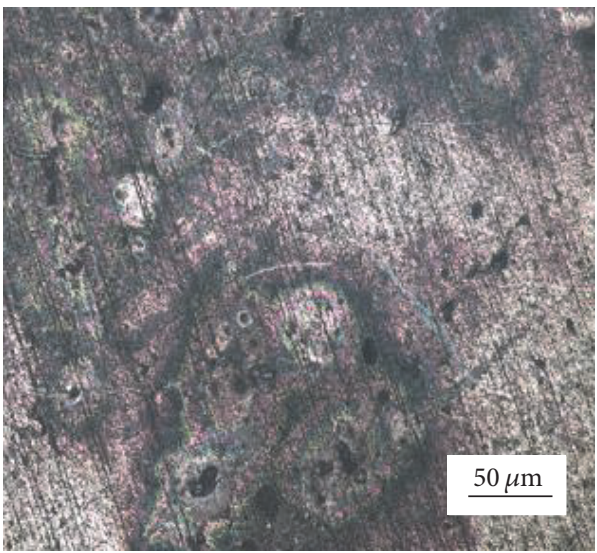

(a)

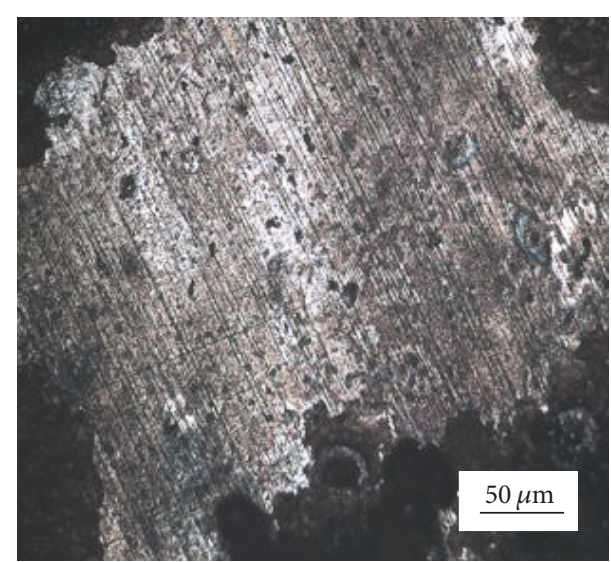

(b)

FIGURE 12: Macroscopic morphology of specimens of (a) BM and (b) WM, immersed in 3.5\% NaCl solution for 7 days.

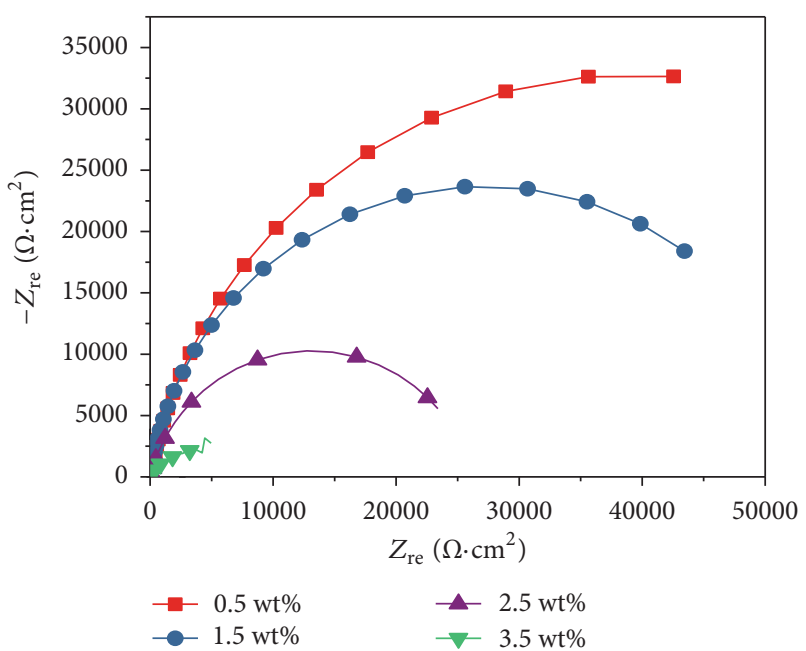

(a)

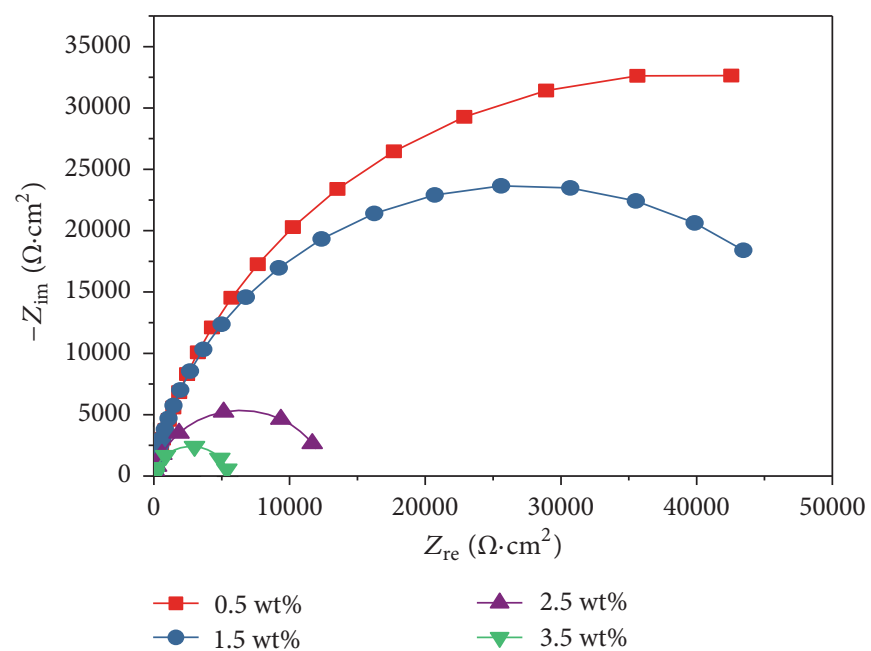

(b)

FIGURE 13: Influence of $\mathrm{Cl}^{-}$concentration on EIS profiles of (a) BM and (b) WM.

concentration results in an increase in the corrosion current density and decrease in the corrosion potential and corrosion resistance of both $\mathrm{BM}$ and WM.

Figure 13 shows the effect of $\mathrm{Cl}^{-}$concentration on the EIS of BM and WM. With the increase in $\mathrm{Cl}^{-}$concentration, the capacitance arc and the polarization resistance gradually decrease, indicating a gradual decrease in corrosion resistance. This result is consistent with those obtained from the polarization curve.

\section{Conclusions}

(1) Welding of girth weld seam of API X80 steel linepipe with thick wall and large diameter has been conducted successfully using the twin-wire PT-GMAW process. The achieved high welding efficiency makes this process an appropriate choice for the welding of the above structure.
(2) With optimized welding parameters, the welded joint exhibits good morphology, mechanical properties, and corrosion resistance. Irrespective of the type of corrosive environment, the corrosion resistance of weld metal is slightly lower than that of the base metal at both the inner and outer surfaces of the API X80 steel linepipe.

(3) The corrosion resistance of the base metal and the weld metal is decreased with the increase in temperature or $\mathrm{Cl}^{-}$concentration.

\section{Conflicts of Interest}

The authors declare that they have no conflicts of interest.

\section{Acknowledgments}

The authors are grateful for the financial supports from the National Natural Science Foundation of China (51305461) 
and the Fundamental Research Funds for the Central Universities (13CX02075A). They would also like to acknowledge the presentation of this manuscript submitted to WSE \& CAWE 2017.

\section{References}

[1] S. Felber, "Welding of the high grade pipeline-steel X80 and description of different pipeline-projects," Welding in the World, vol. 52, no. 5-6, pp. 19-41, 2008.

[2] H. L. Li, L. Ji, and T. W. Kang, "Significant technical progress in the West-East Gas Pipeline Projects - Line One and Line Two," Natural Gas Industry, vol. 30, no. 4, pp. 1-9, 2010.

[3] Y. L. Sui and H. Wu, "Current and future applications of automatic welding technology for long-distance oil/gas pipeline in China," Oil and Gas Storage and Transportation, vol. 33, no. 9, pp. 913-921, 2014.

[4] J.-Y. Yoo, S.-S. Ahn, D.-H. Seo, W.-H. Song, and K.-B. Kang, "New development of high grade X80 to X120 pipeline steels," Materials and Manufacturing Processes, vol. 26, no. 1, pp. 154160, 2011.

[5] S. Gook, A. Gumenyuk, and M. Rethmeier, "Hybrid laser arc welding of X80 and X120 steel grade," Science and Technology of Welding and Joining, vol. 19, no. 1, pp. 15-24, 2014.

[6] M. Zhao, F. Wei, W. Q. Huang, and Y. Lei, "Experimental and numerical investigation on combined girth welding of API X80 pipeline steel," Science and Technology of Welding and Joining, vol. 20, no. 7, pp. 622-630, 2015.

[7] D. P. Fairchild, M. L. Macia, N. V. Bangaru et al., "Girth welding development for X120 linepipe," International Journal of Offshore and Polar Engineering, vol. 14, no. 1, pp. 18-28, 2004.

[8] T. Ueyama, T. Ohnawa, M. Tanaka, and K. Nakata, "Occurrence of arc interaction in tandem pulsed gas metal arc welding," Science and Technology of Welding and Joining, vol. 12, no. 6, pp. 523-529, 2007.

[9] Z. Sterjovski, C. Bayley, J. Donato, N. Lane, and D. Lang, "Weldend solidification cracking in pulsed-tandem gas metal arc welding of naval steels," Welding Journal, vol. 93, no. 5, pp. 145152, 2014.

[10] X. P. Gu, D. Long, and Y. B. Qiu, "Review on anti-corrosion joint coating technology of oil and gas pipelins," Corrosion and Protection, vol. 30, no. 4, pp. 261-264, 2009.

[11] H. Liu and Y. Frank Cheng, "Mechanism of microbiologically influenced corrosion of X52 pipeline steel in a wet soil containing sulfate-reduced bacteria," Electrochimica Acta, vol. 253, pp. 368-378, 2017.

[12] A. F. Ballesteros, J. A. P. Gomes, I. S. Bott et al., "Corrosion evaluation of SAW welded API 5L X-80 joints in $\mathrm{H}_{2} \mathrm{~S}$-containing solution," Materials Research, vol. 18, no. 2, pp. 417-426, 2015.

[13] D. Wang, F. Xie, M. Wu, G. Liu, Y. Zong, and X. Li, "Stress Corrosion Cracking Behavior of X80 Pipeline Steel in Acid Soil Environment with SRB," Metallurgical and Materials Transactions A: Physical Metallurgy and Materials Science, vol. 48, no. 6, pp. 2999-3007, 2017.

[14] I. Bertuccio and M. V. Biezma Moraleda, "Risk assessment of corrosion in oil and gas pipelines using fuzzy logic," Corrosion Engineering, Science and Technology, vol. 47, no. 7, pp. 553-558, 2013.

[15] J. L. Mora-Mendoza, L. C. Saucedo-Robles, H. RodríguezClemente, M. A. González-Núñez, G. Zavala-Olivares, and M. J. Hernández-Gayosso, "Integral diagnostic in the failure causes of external corrosion of a natural gas transport pipeline," Materials and Corrosion, vol. 62, no. 8, pp. 796-801, 2011.

[16] J. Fu, Y. Wang, Y. Li, Y. Lei, and R. Jiang, "Environmental and safety risk management of oil and gas pipelines in their full life cycle," Natural Gas Industry, vol. 33, no. 12, pp. 138-143, 2013.

[17] M. A. Deyab, N. H. Mohamed, and Y. M. Moustafa, "Corrosion protection of petroleum pipelines in $\mathrm{NaCl}$ solution by microcrystalline waxes from waste materials: Electrochemical studies," Corrosion Science, vol. 122, pp. 74-79, 2017.

[18] R. A. Carneiro, R. C. Ratnapuli, and V. de Freitas Cunha Lins, "The influence of chemical composition and microstructure of API linepipe steels on hydrogen induced cracking and sulfide stress corrosion cracking," Materials Science and Engineering: A Structural Materials: Properties, Microstructure and Processing, vol. 357, no. 1-2, pp. 104-110, 2003.

[19] H. Qian, L. Wang, H. Wang, W. Zheng, D. Zhang, and C. Du, "Electrochemical Behavior and Stress Corrosion Sensitivity of X70 Steel Under Disbonded Coatings in Korla Soil Solution," Journal of Materials Engineering and Performance, vol. 25, no. 11, pp. 4657-4665, 2016.

[20] L. L. Liu, J. Xu, and Z. Y. Li, "Electrochemical characterization of $\mathrm{Ti}_{5} \mathrm{Si}_{3} / \mathrm{TiC}$ nanocomposite Coating in $\mathrm{HCl}$ Solution," International Journal of Electrochemicalenc, vol. 8, no. 4, pp. 5086-5101, 2013.

[21] H. Cao, D. Lu, J. Lin, Q. Ye, J. Wu, and G. Zheng, "Novel Sbdoped ruthenium oxide electrode with ordered nanotube structure and its electrocatalytic activity toward chlorine evolution," Electrochimica Acta, vol. 91, pp. 234-239, 2013. 


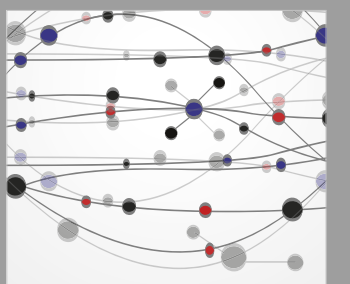

The Scientific World Journal
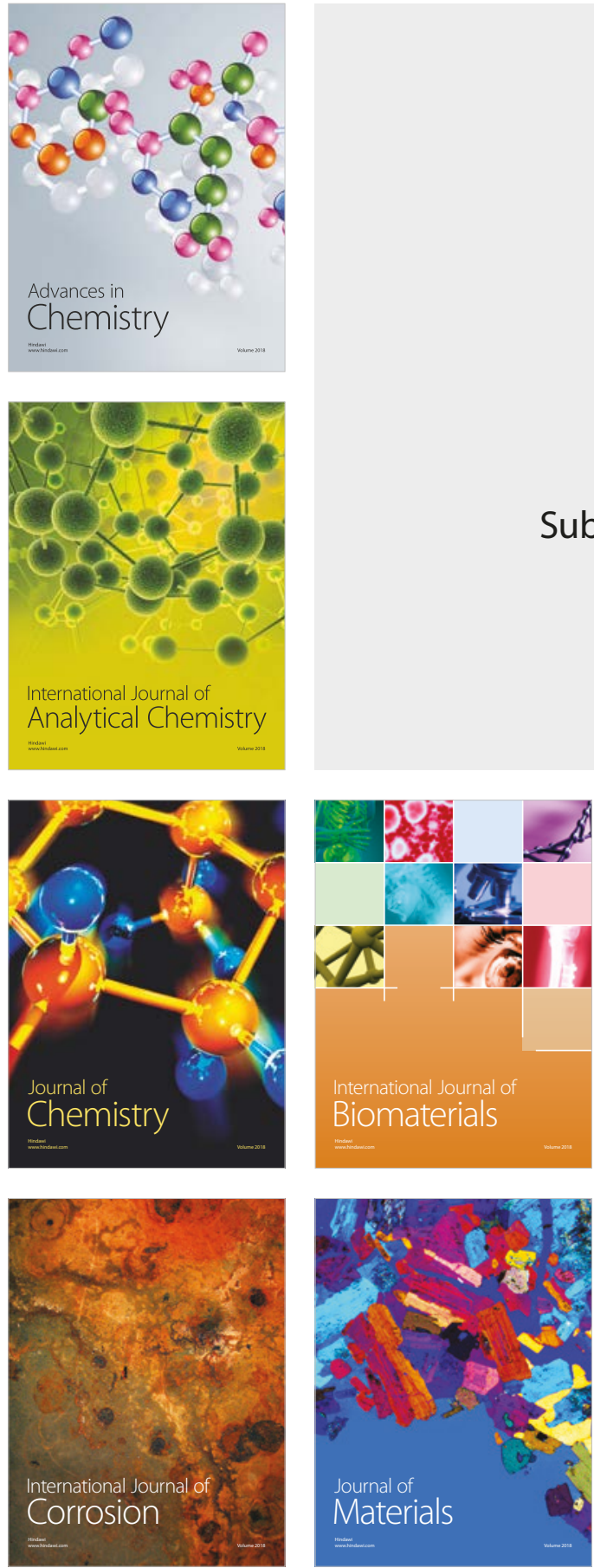

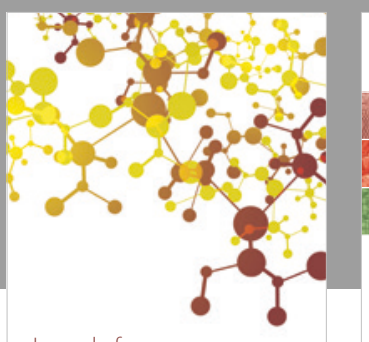

Journal of

Applied Chemistry
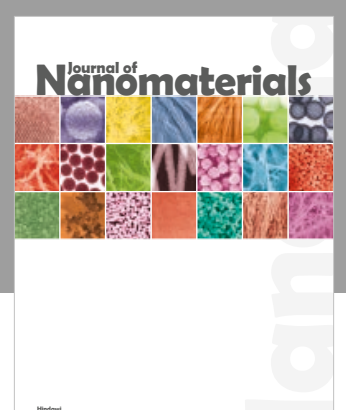

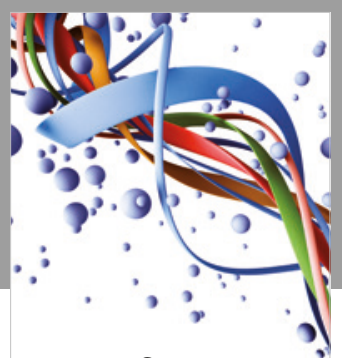

Scientifica

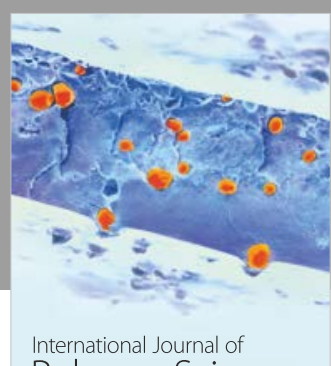

Polymer Science

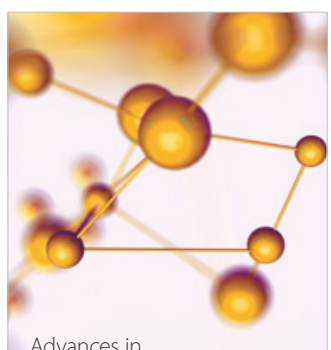

Physical Chemistry
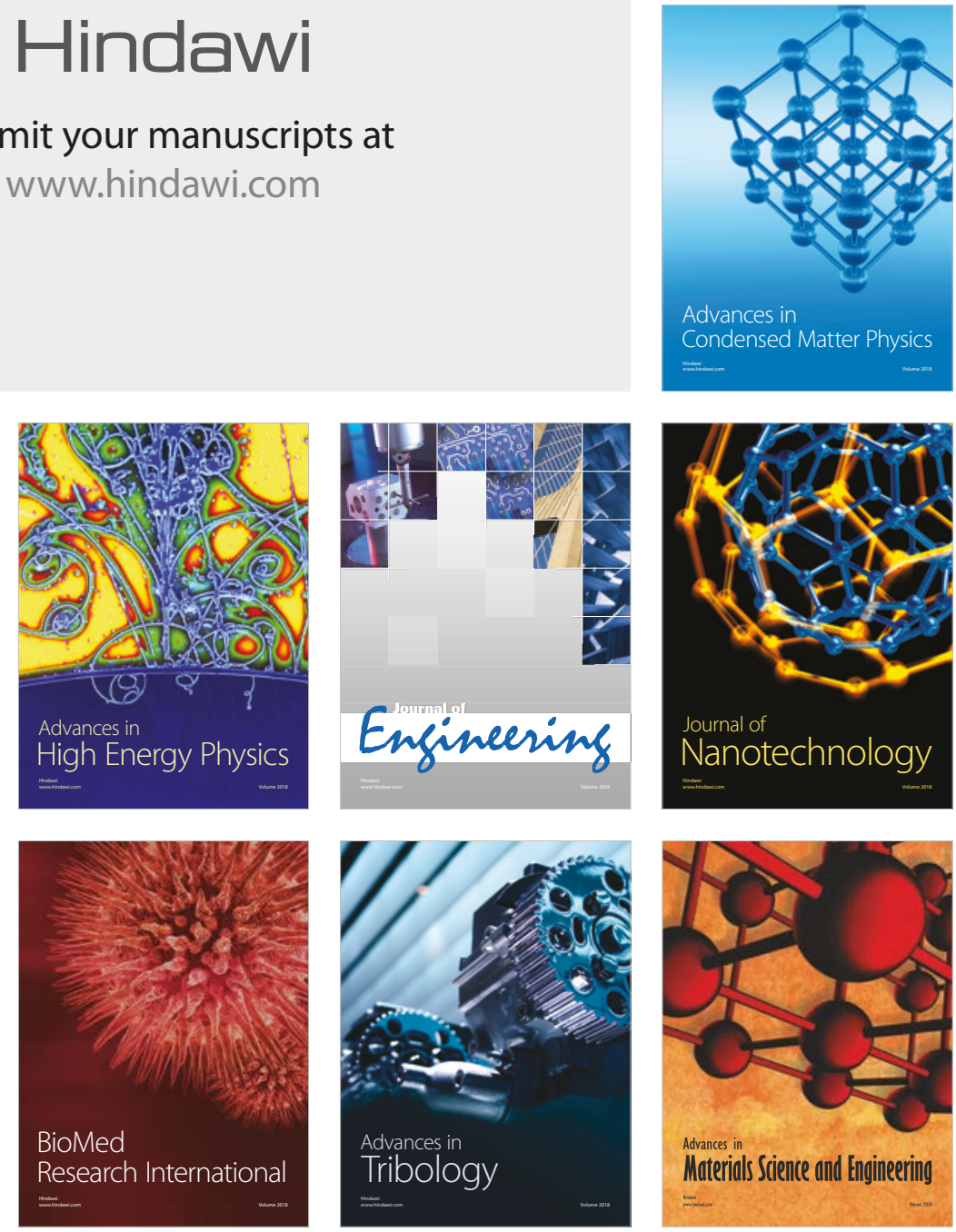